\title{
Extraction of tomato by-products' bioactive compounds using ohmic technology
}

\author{
Marta Coelho ${ }^{a, b}$, Ricardo Pereira $^{b}$, António S. Rodrigues ${ }^{c}$, José A. Teixeira $^{b}$, \\ Manuela E. Pintado ${ }^{a, *}$ \\ a Universidade Católica Portuguesa, $\mathrm{CBQF}$-Centro de Biotecnologia e Química Fina - Laboratório Associado, Escola \\ Superior de Biotecnologia, Rua Diogo Botelho 1327, 4169-005 Porto, Portugal \\ ${ }^{\mathrm{b}}$ CEB-Centre of Biological Engineering, University of Minho, 4710-057 Braga, Portugal \\ c Centre for Toxicogenomics and Human Health, Genetics, Oncology and Human Toxicology, NOVA Medical \\ School/Faculdade de Ciências Médicas, Universidade Nova de Lisboa, Lisbon, Portugal
}

\section{A R T I C L E I N F O}

Article history:

Received 15 April 2019

Received in revised form 24 July 2019

Accepted 7 August 2019

Available online 13 August 2019

\section{Keywords:}

Lycopersicon esculentum

Tomato by-products

Ohmic heating

Extraction optimization

By-products valorization

New extraction method

Polyphenols

Carotenoids

\begin{abstract}
A B S T R A C T
Tomato peels and seeds are the main by-products of the tomato industry and represent an interesting source of bioactive compounds (BC) including carotenoids, which can be then used as colorant to commercial aquaculture. The aim of the present work was to optimize the extraction of $\mathrm{BC}$ from tomato by-products using Ohmic heating $(\mathrm{OH})$ technology. $\mathrm{OH}$ extraction experiments were done in the presence of moderate electric fields (MEF) of different intensity (i.e. 4,6 and $11 \mathrm{~V} \mathrm{~cm}^{-1}$ ) to identify the presence of non-thermal effects on the extraction process and its influence on bioactive properties of the extracted compounds. Polyphenol extraction using $\mathrm{OH}$ was successfully optimized with the best extraction conditions being $70^{\circ} \mathrm{C}$ for $15 \mathrm{~min}$ using $70 \%$ ethanol as a solvent, which exhibited rutin recovers of $77 \%$ higher than control samples. It allowed to recover up to $4.93 \mu \mathrm{g} / \mathrm{gFW}$ lycopene from tomato by-products without resorting to organic solvents. $\mathrm{OH}$ can be used as an environmental-friendly, fast and economic process to polyphenols recover from industrial tomato by-products. In addition, the use of different MEF during extraction shows to have a high potential to cause different levels of permeabilization and cell stress that can help to define a selective extraction process of valuable components from tomato by-products.
\end{abstract}

(C) 2019 Institution of Chemical Engineers. Published by Elsevier B.V. All rights reserved.
1. Introduction

Annual tomatoes (Lycopersicon esculentum) production worldwide is 170 million tons, which 127.5 million are for the fresh consumption and 42.5 million are for the industrial processing, being one of sectors with the greatest impact in the agro-food industries (FAO, 2017; Heuvelink, 2018). Processed tomato products often result in higher amounts of by-products, namely, skin, pulp and tomato seeds. They are excellent sources of bioactive compounds (BC), such as vitamins, $\beta$-carotene, lycopene, flavonoids, which can be used as synthesis of pharmaceutical, colorants and food products (Figueiredo-González et al., 2016; Galanakis, 2017).
However, current extraction treatments involve application of solvents and leaching, which besides being a hazard to the environment, can cause degradation of these compounds, promote their toxicity and reduce their biological properties and health benefits, thus hampering their added value (Ameer et al., 2017; Caldas et al., 2018; Tommonaro et al., 2008). Therefore, it is imperative to search for new alternatives for extraction methods that can bring added value to these by-products. $\mathrm{OH}$ is one of these emergent extraction method, and is based on passage of alternating electrical current through semiconductive materials allowing the generation of internal heat due to inherent electric resistance of the product to be treat (Brochier et al., 2018; Gavahian et al., 2016; Pereira et al., 2016; Seidi Damyeh and Niakousari, 2017)

\footnotetext{
* Corresponding author.

E-mail address: mpintado@porto.ucp.pt (M.E. Pintado).
}

https://doi.org/10.1016/j.fbp.2019.08.005

0960-3085/@ 2019 Institution of Chemical Engineers. Published by Elsevier B.V. All rights reserved. 
$\mathrm{OH}$ has great potential for achieving rapid, uniform and precise heating in foods, providing a wide range of food processing applications including pasteurization, sterilization, microbial inactivation, fermentation, cooking, blanching, thawing, starch gelatinization, enzyme stabilization (Anderson and Finkelstein, 1919; Kumar, 2018; Pereira et al., 2018, 2016).

It may be very attractive to enhance the extraction of BC with lower energetic costs (>95\% of energetic efficiency) and better product quality (Brochier et al., 2018; El Darra et al., 2013; Hogervorst Cvejić et al., 2017a; Pereira et al., 2018). Nevertheless, there is a great gap in knowledge between the interaction of the electric field and the BC, e.g. if the electric fields are sufficiently to cause bound-breaks, change chemical structures and BC degradation, or regarding cell wall can cause differences in its permeability and increases extraction, being imperative studies to verify the effect of the $\mathrm{OH}$ in these compounds.

This technology is not possible to apply in non-conductive food systems, as well as, it is also difficult to apply it in non-homogeneous food systems. Furthermore, many systems/foods are rich in proteins can lead to deposit formation on the surface of $\mathrm{OH}$ electrodes, that if not properly cleaned can result in an electrical arcing. The disadvantages aforementioned can be easily controlled (Kumar, 2018; Ramaswamy et al., 2014).

Although $\mathrm{OH}$ has been applied for some time, there are few studies on its influence as an extraction method of bioactive polyphenols and carotenoids from tomato by-products (Hogervorst Cvejić et al., 2017b; Rajha et al., 2014).

Hence, in the present work, the influence of $\mathrm{OH}$ and moderate electric fields (MEF) of different intensities, in the extraction of $\mathrm{BC}$ from tomato by-products were evaluated in order to value this fraction in a sustainable industry system.

\section{Material \& methods}

\subsection{Samples}

Fresh samples of industrial tomato by-products (seeds and skins) were collected from the company Sugalidal in Santarém, Portugal. After being collected, the dry matter of samples was measured, and by-products were stored at $-80^{\circ} \mathrm{C}$ until further analysis.

\subsection{Extraction strategy evaluation}

In order to understand best approach to $\mathrm{OH}$ technology (using as pre-treatment step, A and B, followed by extraction at room temperature or by assisting thermal-extraction, C) an initial set of tests were performed. For pre-treatment $\mathrm{A}, \mathrm{OH}$ was applied directly to $2.5 \mathrm{~g}$ of tomato by-products; in this case the maximum temperature which system was able to achieve was of $55^{\circ} \mathrm{C}$ (with a holding time of $1 \mathrm{~min}$ ). This temperature was then used for the remaining treatments for a proper comparison. For pre-treatment B, $2.5 \mathrm{~g}$ of tomato by-products were previously washed in a $0.1 \mathrm{M}$ sodium chloride solution (NaCL) before $\mathrm{OH}$ application in the solid residue (with a holding time of $1 \mathrm{~min}$ ) this treatment allows the increase of extract conductivity and also allows reach at $55^{\circ} \mathrm{C}$ in short time; in both pre-treatment $\mathrm{A}$ and $\mathrm{B}$ the extraction was then performed with $12.5 \mathrm{~mL}(1: 6 \mathrm{w} / \mathrm{v})$ of $70 \%$ water:ethanol absolute solution (during $0,10,20$ and $30 \mathrm{~min}$ ) at $55^{\circ} \mathrm{C}$. For $\mathrm{C}$, an $\mathrm{OH}$ assisted extraction was performed by combining the same solvent solution prepared before $(70 \%$ of water:ethanol absolute (v/v) with $\mathrm{OH}$ at $55^{\circ} \mathrm{C}$. For all the water:ethanol extraction was performed for 0 (only the time to reach target temperature), 10,20 and $30 \mathrm{~min}$.

\subsubsection{Ohmic heating extraction}

A cylindrical glass reactor with $30 \mathrm{~cm}$ total length, an inner diameter of $2.7 \mathrm{~cm}$ and two stainless steel electrodes placed at each edge isolated by polytetrafluoroethylene (PTFE) caps, were used to $\mathrm{OH}$ assisted extraction from tomato samples, as referred by Pereira et al. (2016). The supplied voltage ranged from 60 to $280 \mathrm{~V}$, during $30 \mathrm{~min}$, with different temperatures $\left(0-100^{\circ} \mathrm{C}\right)$. Electrodes used stainless steel 316 and $\mathrm{OH}$ was performed at $25 \mathrm{kHz}$. This combination avoid corrosion and electrochemical reactions (Pataro et al., 2014). A function generator (Agilent 33,220 A, Bayan Lepas, Malaysia; $1 \mathrm{~Hz}-25 \mathrm{MHz}$ and 1-10V) connected to an amplifier system (Peavey CS3000, Meridian, MS, USA; 0.3 V-170 V) was used to control system.

\subsubsection{Conventional heating (COV)}

A reactor vessel with double-walled ( $3 \mathrm{~mm}$ of internal diameter and $100 \mathrm{~mm}$ height) was coupled with a circulating thermo-stabilized water bath to perform conventional extraction at controlled temperature, as reported previously (Pereira et al., 2010).

Both methods ( $\mathrm{OH}$ and conventional) presented a similar thermal history as well as the same solutions were used. All procedures were recorded to ensures having exactly similar conditions for both methods.

\subsection{Total antioxidant capacity and phenolic content}

Total antioxidant activity (AA) was determined using the ABTS method as described by Gião et al. (2007). The results were given in ascorbic acid equivalent.

The total content of polyphenol compounds (TPC) in the extracts was evaluated through the Folin - Ciocalteu spectrophotometric method as described by Singleton and Rossi (1965) and expressed as milligram of gallic acid equivalent.

\subsection{Total carotenoids}

Total carotenoids (TC) was assed using a spectrophotometric analysis, as described by Kimura et al. (1990) and are expressed in equivalent $\beta$-carotene.

\subsection{Color}

The nonspecific turbidity was determined by optical density at $600 \mathrm{~nm}$ using a Versamax Elisa microplate reader with polystyrene 96-well microplates (Nunc, Denmark) as described by Hodges et al. (1999).

\subsection{HPLC-analysis}

Qualitative and quantitative profiles of polyphenols were carried out according to the method proposed by Oliveira et al. (2015), with slight modifications. Analysis was conducted on HPLC-DAD (Waters Series 600. Mildford MA. USA). A Symmetry ${ }^{\circledR}$ C18 column, $250 \times 4.6 \mathrm{~mm}$ i.d. $5 \mu \mathrm{m}$ particle size and $125 \AA$ pore size with a guard column (waters), was used and solvents elution consisted of solvent A - Acetonitrile $(100 \%)$ with $0.2 \%$ TFA; Solvent B: acetonitrile/water (5:95 v/v) (Merck pure grade and pure water) with $0.2 \%$ TFA (Sigma-Aldrich, Germany); Samples were analyzed in triplicate. Calibration curves were obtained at a detection wavelength $280 \mathrm{~nm}$. Standards solutions over the concentration range from 0.10 to $100.00 \mathrm{mg} / \mathrm{L}$ were prepared for the identification and quantification of the following compounds: 
rutin, naringenin and Kaempferol (Sigma, Sintra, Portugal) expressed as $\mu \mathrm{g}$ per $\mathrm{mL}$ of fresh weight (FW) biomass of tomato. All calibration curves were linear over the concentration ranges tested, with correlations coefficients of 0.999 .

Carotenoids content was also analysed by HPLC-DAD (Vydac 201TP54 C-18 column, $250 \mathrm{~mm}-4.6 \mathrm{~mm}$ ), equipped with a C-18 precolumn.

Chromatographic separation was performed as described by Oliveira et al. (2004). Solvent A with ethyl acetate (Merck pure grade) and solvent B 90:10 acetonitrile:water (Merck pure grade and pure water, $1.0 \mathrm{~mL} / \mathrm{min}$ flow rate, at room temperature.

The UV-vis detector was set between 270 and $550 \mathrm{~nm}$. Individual carotenoids were quantified and from a calibration curve built with pure standards: $\beta$-carotene, lycopene, zeaxanthin and lutein (Extrasynthese, Genay Cedex, France) and expressed as milligrams per kilogram of fresh product.

\subsection{Extraction optimization}

Based on results obtained according methodologies applied in Sections 2.2.1 and 2.2.2 and to better understand both temperature, organic solvents ratio and time effects on bioactive compounds extraction a design of experiments (DOE) was now applied. Twelve experimental combinations were determined according custom design, $n=2^{3}$, consisting of a $3^{3}$ factorial design with three levels $(-1,0,+1)$. The independent variables were as follows: time $(0-30 \mathrm{~min})$; temperature $\left(35^{\circ} \mathrm{C}-100^{\circ} \mathrm{C}\right)$; and percentage of solvent (0-70\%). Total phenolic compounds, antioxidant activity, total carotenoids and color were used as dependent variables. Table 1 shows the combination of the different independent experimental variables.

Based on data from phenolic, antioxidant and carotenoids compounds, and overall linking, a response surface was fitted to data, by adjusting a quadratic polynomial equation (Eq. (1)):

$$
\begin{aligned}
y & =b_{0}+b_{1} x_{1}+b_{2} x_{2}+b_{3} x_{3}+b_{11} x_{1}^{2}+b_{22} x_{2}^{2}+b_{33} x_{3}^{2}+b_{12} x_{2} x_{3} \\
& +b_{13} x_{1} x_{2}+b_{23} x_{1} x_{3}
\end{aligned}
$$

were $b_{0}$ represents the constant term, $b_{1}, b_{2}$ and $b_{3}$ linear effects, $b_{21}, b_{22}$ and $b_{33}$, represents quadratic effects and $b_{12}$, $b_{13}$ and $b_{23}$ the interaction effects, namely, time $\left(x_{1}\right)$ temperature $\left(\mathrm{x}_{2}\right)$ and ethanol $\left(\mathrm{x}_{3}\right)$. ANOVA was performed in order to assess the regression coefficients used.

\subsection{Moderate electric fields (MEF) effects}

The $\mathrm{OH}$ in concomitance with MEF can causes changes on polyphenols and carotenoids. Thus, after determining the best extraction process with the experimental design, the impact of temperature and MEF intensity on BC extraction was assessed. Three sodium salt concentrations $(0.514,0.257$ and $0.120 \mathrm{~mol} / \mathrm{L}$ ) were added to the extraction solutions to increase the electrical conductivity and to allow working at different electric field strengths - i.e. 4,6 and $11 \mathrm{~V} \mathrm{~cm}^{-1}$, respectively, thus ensuring the generation of heat within the mixture (Table 2). Three levels of MEF were used at the same temperature profile in order to evaluate possible non-thermal effects of the $\mathrm{OH}$. An experiment was also performed where a maximum voltage was applied on solution with moderate electric conductivity $(0.257 \mathrm{~mol} / \mathrm{L})$ in order to create a fast $\mathrm{OH}$ extraction and decrease the thermal load of $\mathrm{OH}$ (by this procedure, the extraction temperature was reached very fast, in $2 \mathrm{~s}$; the voltage was immediately reduced to maintain the temperature). The conventional extraction method (without the presence of electrical variables) was performed in the solutions of different electrical conductivities benchmarking all $\mathrm{OH}$ performed. All experiments were done in triplicated.

\subsection{Statistical analysis}

Data analyses were performed using STATISTICA software v.12 (StatSoft, Inc., USA) and STATGRAPHICS Centurion software v. XVI.I. A descriptive statistics (mean and standard deviation) were performed, and a two-way ANOVA was applied at a $95 \%$ confidence level.

The Multiple Factor Analysis (MFA) was applied to assess the consensus among the different variables analysed: total phenolic compounds, antioxidants, colour and carotenoids. Additionally, aggregated data was used to perform a PCA, identifying major relationships between variables.

A screening of DOE was executed considering the responses obtained. Moreover, to elaborate the predictive statistic model, according to Rsquare and Rsquare adjusted values, the independent variables that influenced the dependent variables behaviour were selected. Finally, optimal conditions were obtained by settings desirability values to each responses type to obtain maximum desirability. Additional trials at the optimum predicted conditions were performed in order to validate the models obtained and experimental results were compared with the predicted ones.

All analysis was performed in triplicated and a standard deviation was calculated.

\section{Results and discussion}

\subsection{Influence of extraction conditions}

In this study, a solvent system based on water-ethanol was used to attain a green extraction of the BC polyphenols and carotenoids from tomato by-products. In the first part of this study, $\mathrm{OH}$ was used as pre-treatment preceding the extraction with water/ethanol at $55^{\circ} \mathrm{C}$ in an in attempt to soften tomato tissues, but an increase in the contents of total carotenoids and total phenolics of the extracts were only observed during $\mathrm{OH}$-assisted extraction with water/ethanol (Fig. 1).

The application of $\mathrm{OH}$ pre-treatments was reported to induce the permeabilization of cell membranes and facilitate the polyphenolic extraction with ethanol addition (El Darra et al., 2013). Nevertheless, this sample is solid and poorly conductive, which requires applying higher electric fields to the temperature reaching $55^{\circ} \mathrm{C}$, leading to a degradation of the most sensitive compounds such as carotenoids. During this process, several mechanisms may be occurred, including a highest internal heating of samples, electrode reactions and the electrolysis of samples, thus the BC degradation was caused by heat and by electrochemical degradation. In addition, both degradation reaction mechanisms and kinetic parameters may be influenced by reactions between the electrode materials and the electrolysis products (Kaur et al., 2016a). In this way we consider the treatment $C$ an opportunity to develop a new method for BC extraction. Furthermore, several studies, have reported that the recovery of different BC, such as polyphenols and carotenoids, depends both on the treatment time and temperature, as well as solvents used (Lapornik et al., 2005). This information together with the 
Table 1 - Experimental combinations of temperature, time and \% of ethanol of tomato wastes obtained from experimental design and the total carotenoids equivalent of $\beta$-carotene and lycopene in extracts from tomato by-products.

\begin{tabular}{lllll} 
Temperature $\left({ }^{\circ} \mathrm{C}\right)$ & Time $(\mathrm{min})$ & Ethanol $(\%)$ & Total carotenoids $(\mathrm{mg}$ eq. $\beta$-caroten/g FW) & Lycopene $(\mu \mathrm{g} / \mathrm{gFW})$ \\
\hline 40.0 & 0.0 & 0.0 & $0.080 \pm 0.012^{\mathrm{d}}$ & $2.253 \pm 0.002^{\mathrm{c}}$ \\
40.0 & 15.0 & 70.0 & $0.178 \pm 0.011^{\mathrm{b}}$ & n.d. \\
40.0 & 30.0 & 35.0 & $0.195 \pm 0.020^{\mathrm{a}, \mathrm{b}}$ & n.d. \\
55.0 & 0.0 & 70.0 & $0.126 \pm 0.017^{\mathrm{c}}$ & n.d. \\
55.0 & 15.0 & 35.0 & $0.237 \pm 0.085^{\mathrm{a}}$ & $4.926 \pm 0.003^{\mathrm{b}}$ \\
55.0 & 30.0 & 0.0 & $0.093 \pm 0.007^{\mathrm{c}}$ & $2.339 \pm 0.001^{\mathrm{c}}$ \\
70.0 & 0.00 & 35.0 & $0.096 \pm 0.005^{\mathrm{c}}$ & $4.772 \pm 0.011^{\mathrm{b}}$ \\
70.0 & 15.0 & 0.0 & $0.163 \pm 0.031^{\mathrm{b}, \mathrm{c}}$ & n.d. \\
70.0 & 30.0 & 70.0 & $0.099 \pm 0.003^{\mathrm{c}, \mathrm{d}}$ & $2.939 \pm 0.002^{\mathrm{c}}$ \\
55.0 & 15.0 & 35.0 & $0.116 \pm 0.027^{\mathrm{c}}$ & $2.566 \pm 0.003^{\mathrm{c}}$ \\
55.0 & 15.0 & 35.0 & $0.115 \pm 0.010^{\mathrm{c}}$ & $7.108 \pm 0.122^{\mathrm{a}}$ \\
55.0 & 15.0 & 35.0 & $0.133 \pm 0.040^{\mathrm{c}}$ & $2.521 \pm 0.001^{\mathrm{c}}$ \\
70.0 & 15.0 & 35.0 & $0.240 \pm 0.006^{\mathrm{a}}$ & n.d. \\
\hline
\end{tabular}

Values were present as mean \pm SD. ${ }^{a}$ Different letter represent significant differences $(p<0.05)$ in comparison to the original content.

Table 2 - Ohmic and conventional treatments applied on by-products from tomato (temperature, time, ethanol, conductivity, salt concentration and electric field).

\begin{tabular}{|c|c|c|c|c|c|c|c|}
\hline Assay nr. & Treatment & Temperature $\left({ }^{\circ} \mathrm{C}\right)$ & Time (min) & Ethanol (\%) & $\begin{array}{l}\text { Conductivity } \\
\left(\mathrm{ms} \mathrm{cm}^{-1}\right)\end{array}$ & $\begin{array}{l}\text { Salt concentration } \\
(\mathrm{mol} / \mathrm{L})\end{array}$ & $\begin{array}{l}\text { Electric field } \\
\left(\mathrm{V} \mathrm{cm}^{-1}\right)\end{array}$ \\
\hline 1 & Conventional & 70 & 15 & 70 & 1.00 & 0.12 & $\mathrm{n} / \mathrm{a}$ \\
\hline 2 & Conventional & 70 & 15 & 70 & 3.99 & 0.25 & $\mathrm{n} / \mathrm{a}$ \\
\hline 3 & Conventional & 70 & 15 & 70 & 8.17 & 0.51 & $\mathrm{n} / \mathrm{a}$ \\
\hline 4 & $\mathrm{OH}$ & 70 & 15 & 70 & 1.00 & 0.12 & 11 \\
\hline 5 & $\mathrm{OH}$ & 70 & 15 & 70 & 3.99 & 0.25 & 6 \\
\hline 6 & $\mathrm{OH}$ & 70 & 15 & 70 & 8.17 & 0.51 & 4 \\
\hline 7 & $\mathrm{OH}$ & 70 & 1 & 70 & 3.99 & 0.25 & 6 \\
\hline 8 & Control & 25 & 15 & 70 & 1.00 & 0.12 & $\mathrm{n} / \mathrm{a}$ \\
\hline 9 & Control & 25 & 15 & 70 & 3.99 & 0.25 & $\mathrm{n} / \mathrm{a}$ \\
\hline 10 & Control & 25 & 15 & 70 & 8.17 & 0.51 & $\mathrm{n} / \mathrm{a}$ \\
\hline
\end{tabular}

results obtained was decisive to study the potential of $\mathrm{OH}$ for $\mathrm{BC}$ recovery, due its ability to achieves fast and relatively uniform heating rates. Thus, the treatment $C$ was used for the following experiments.

\subsection{Extraction optimization}

The agro-industrial sector is interested in the development of affordable green extraction processes, that reduce/eliminated the organic solvents and elevated temperatures (Ribeiro et al., 2015). Furthermore, the extraction efficiency of BC, is affected by their chemical nature, particle size, solvent and extraction method (type of solvent, polarity, $\mathrm{pH}$, temperature, extraction time) used and the synergy due the presence of interfering substances (Do et al., 2014). Accordingly, for the second part of this work, the effect of $\mathrm{OH}$ with various treatment times, temperatures and concentrations of ethanol on the antioxidant activity, polyphenols and carotenoids were evaluated. An experimental design was constructed to reduce the number, time and cost of the experiments.

\subsubsection{Experimental modelling and statistics}

All response values were demonstrated by statistical analysis to fit best the quadratic order polynomial equations expressing the relation between the experimental parameters and the response variables. The regression models were used to fit a linear model and consequently the data. Furthermore, the adjusted model was adequate and a good representation of the behaviour of the system, with $R^{2}$ values for antioxidant capacity, total polyphenols, total carotenoids and color of $0.97,0.98,0.53$ and 0.76 , respectively. Significant parame- ters affecting thermal extraction process are highlighted in Table 1.

According experimental model, the better conditions to obtain higher antioxidant capacity with application of $70^{\circ} \mathrm{C}$, $70 \%$ of ethanol during 15 min of extraction (Table 3 ).

To total polyphenolic content R-quadratic, explain $98.0 \%$ of total polyphenols variability. The standard error of the estimate shows that the standard deviation of the residues is 0.084. The absolute mean error (MAE) of 0.055 is the average value of the residuals.

The R-squared statistic indicates that the model, thus adjusted, explains $76.4 \%$ of the variability in color. The adjusted R-squared statistic, which is more adequate to compare models with different number of independent variables, is $69.0 \%$. The standard error of the estimate shows that the standard deviation of the residues is 0.05 . The absolute mean error (MAE) of 0.032 is the average value of the residues.

Where the values of the variables are specified in their original units.

Results showed a high degree of correlation between all observed and predicted values, indicating a reasonable agreement of the corresponding model with the experimental results was found.

The results showed that, the variables have different weights for each parameter studied; for instance, the ethanol concentration is the main parameter controlling color intensity and extraction of AA, TPC, while, for carotenoids extraction the most significant variable is the temperature. This may be attributable to the higher content of non-phenolic compounds present in tomato by-products. Fur- 



Fig. 1 - Influence of different ohmic treatment (same electric field applied, $6 \mathrm{~V} \mathrm{~cm}^{-1}$ ) approaches on color, carotenes and total phenolic compounds-A) OH treatment directly applied on tomato by-products; B) $\mathrm{OH}$ applied to samples of tomato by-products previously merged in $\mathrm{NaCl}$; $\mathrm{C}$ ) $\mathrm{OH}$ treatment on samples constituted by tomato by-products samples and a solution of water:ethanol. ${ }^{a}$ Different letters represent significant differences $(p<0.05)$ in comparison to the original content.

Table 3 - Statistical analysis of the effects of temperature, time and ethanol percentage on antioxidant capacity, phenolic content, total carotenoids and colour of tomato by-products.

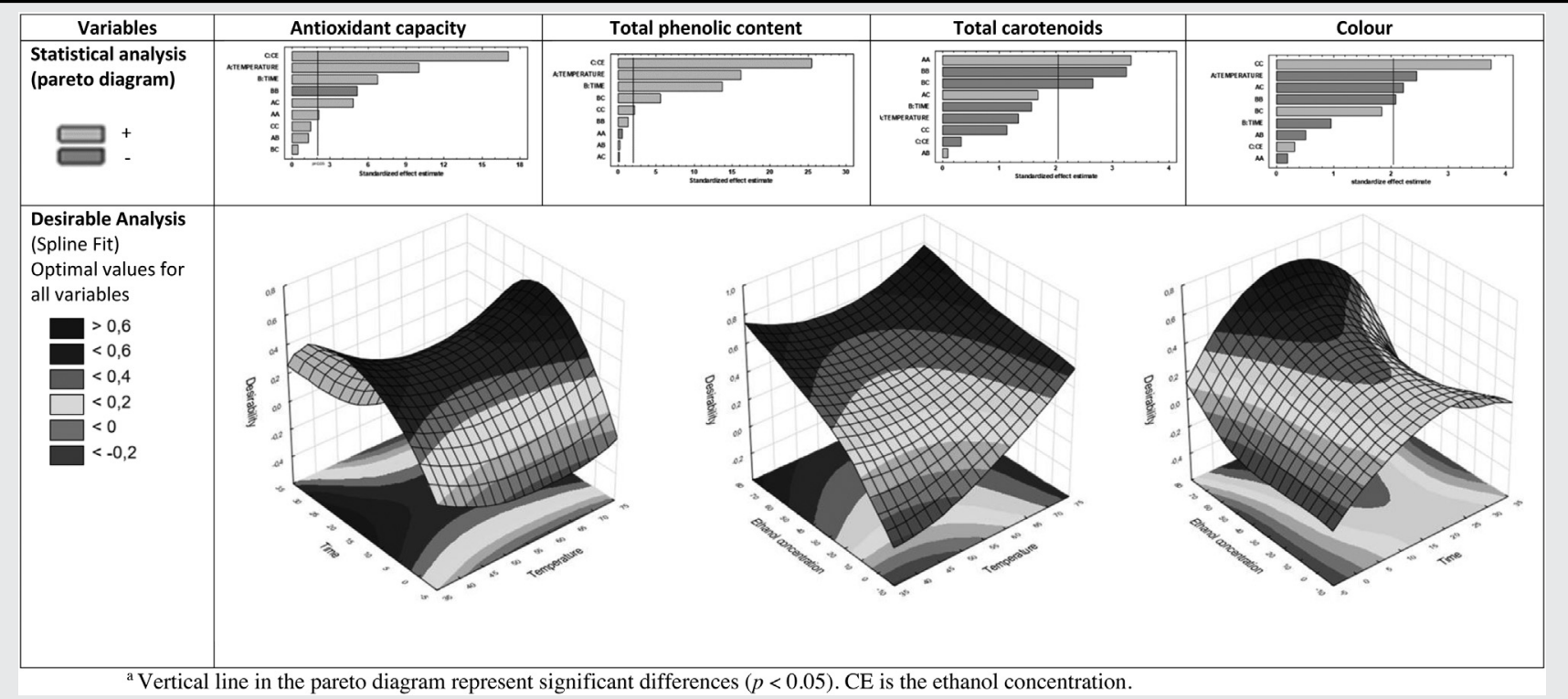

thermore, these extracts are rich in lipophilic molecules, mainly sterols, terpenes and carotenes, which are more soluble in organic solvents (ethanol) (Do et al., 2014). To better understand the results and to obtain the optimum condition, of temperature, holding time and ethanol percentage, to extract simultaneously the maximum concentration of variable dependents (antioxidant activity, total and individ- ual phenolic compounds, carotenoids) a desirability function was applied (Table 3). This function is based on transformation of the original each response in a dimension desirability scale, assigning values between 0 (undesirable value) and 1 (completely desirable/ ideal response value) (Coelho et al., 2017). The optimum extraction conditions found is described below. 


\subsubsection{Total antioxidant activity and polyphenols content}

To determine the best conditions of extraction, as previously described, an experimental design was performed with different conditions of time, temperature and ethanol concentration using an $\mathrm{OH}$ system. The results of antioxidant activity show that ethanol concentration influences the antioxidant activity, followed by the temperature and time $(p<0.05)$ (Table 3). A significant difference was observed between the effects of temperature and ethanol concentration $(p<0.05)$.

In accordance with different conditions of DOE the AA ranged from 0.106 to $1.920 \mathrm{mg} / \mathrm{g} \mathrm{FW}$, and this is in accordance with the published literature. Toor \& Savage reported concentrations of AA ranging from 15.7 and $0.186 \mathrm{mg} / \mathrm{g}$ FW in skins of tomatoes (Toor and Savage, 2005). For TPC they found concentrations ranging from 0.244 to $2.558 \mathrm{mg} \mathrm{GAE} / \mathrm{g} \mathrm{FW}$ which is in accordance with our results. Higher values of TPC and AA may be found in ethanol extracts when compared with water extracts, due the lower polarity of ethanol than water. Cell walls and seeds have unipolar character and for this reason ethanol is more efficient in recovery of polyphenol compounds (Lapornik et al., 2005). An increase of TPC was also revealed with temperature and percentage of ethanol; extraction performed at $70^{\circ} \mathrm{C}$ with $70 \%$ of ethanol during $15 \mathrm{~min}$ gave rise to $2.821 \pm 0.211 \mathrm{mg}$ gallic acid equivalents $/ \mathrm{g} F$, a much higher value than the value of $0.403 \pm 0.019 \mathrm{mg}$ gallic acid equivalents/ $\mathrm{g} F \mathrm{~F}$ in the control $\left(40^{\circ} \mathrm{C}, 0 \mathrm{~min}, 0 \%\right.$ ethanol).

In this way, the response surface analysis showed that the percentage of ethanol influenced both antioxidant activity and phenolic compounds extraction (Table 3), being in accordance with results reported by(Lapornik et al., 2005).

Temperature and time have also significant effects on total polyphenols extraction $(p<0.05)$; polyphenolic content increases with increasing temperature. As mentioned before, these by-products extracts are rich in lipophilic compounds that could form complexes with polyphenolic compounds thus enhancing their solubility in ethanol (Do et al., 2014).

The results obtained indicate that treatment temperatures of $70^{\circ} \mathrm{C}$ are suitable for the extraction of compounds (higher content of phenolics), with higher antioxidant capacity and distinctive phenolic composition when compared to the extraction at $40-55^{\circ} \mathrm{C}(p<0.05)$. The combination of the different factors showed that to obtain higher levels of extraction of total phenolics treatment conditions should be as follow: $70{ }^{\circ} \mathrm{C}$, during $15 \mathrm{~min}$ with $69.9 \%$ of ethanol. The combination of $\mathrm{OH}$ and temperature can be an effective alternative method for extraction of phenolic compounds, which supports other studies (El Darra et al., 2013; Khajehei et al., 2017; Loypimai et al., 2015; Pereira et al., 2016).

\subsubsection{Carotenoids content}

In accordance with results of total carotenoids, temperature and time had a positive and a negative quadratic effect, respectively, resulting in the increase of carotenoid levels with increasing temperature and a maximum recovery capacity of these compounds (mainly lycopene and $\beta$-carotene) is reached independently of extraction time. In addition, the results for individual carotenoids showed that depending on the conditions the lycopene may be or not extracted (Tables 1 and 3). Both temperature and time are key for non-degradation of lycopene (Aguilar-Machado et al., 2017). According desirable analysis the best conditions to extract carotenoids are $55^{\circ} \mathrm{C}$ with $70 \%$ of ethanol during $15 \mathrm{~min}$. The type of solvent and the number of extractions have a significant impact on lycopene extraction due the draw water capacity, while time and sol- vent to sample ratio have no significant effect (Nunes and Mercadante, 2004). Nunes and Mercadante (2004), evaluated lycopene extraction with ethanol and ethyl acetate, with ethyl acetate being more efficient. The carotenoid concentration ranged from 0.0284 to $0.0935 \mathrm{mg} / \mathrm{g}$ FW.

Low temperatures (ambient $23^{\circ} \mathrm{C}$ ), may cause degradation due to oxidation without isomerization (Aguilar-Machado et al., 2017; Hackett et al., 2004), while at higher temperatures $\left(125^{\circ} \mathrm{C}\right)$ isomerization of lycopene may occur with associated losses (Oliveira et al., 2015a, b; Seybold et al., 2004). Dewanto et al. (2002) refers that at $88^{\circ} \mathrm{C}$ lycopene bioavailability is improved when compared with lycopene in fresh tomatoes. Furthermore, lycopene forms complexes with insoluble fiber located in the outer pericarp and the skin (Dewanto et al., 2002). These results are very interesting and open a door for new studies on the effect of time and temperature on lycopene degradation.

\subsubsection{Color}

Red color intensity mainly depends on ethanol concentration and temperature of extraction (Table 3). A positive quadratic effect was shown with increasing of ethanol, while increasing temperature extraction has a significant negative linear effect $(p<0.05)$. In addition, a negative quadratic effect related with the time extraction was also significant $(p<0.05)$. These results suggest a saddle point concerning the effects of temperature, time and ethanol concentration on color intensity. These results were somehow expected due the relationship between color and the main responsible by the color present in tomato, the carotenoids (Kim and Chin, 2016).

\subsection{Electric field effects on $B C$ extraction from tomato}

Electrical processes are gaining an increasing interest for its application in food processing, including the extraction of polyphenols (Kaur and Singh, 2016). Nevertheless, little is known about the impact of electric fields on structural changes of by-products samples or BC, which also may compromise its bioavailability and extraction. Furthermore, some BC are very thermally sensitive and unstable, such as flavonoids and carotenoids and can degrade with the voltage application. Thus, distinct levels of electric field intensity were applied during thermal extraction, namely 4, 6 and $11 \mathrm{~V} \mathrm{~cm}^{-1}$ and optimal conditions determined before $\left(70^{\circ} \mathrm{C}\right.$ for $15 \mathrm{~min}$ using $70 \%$ ethanol). A multivariate analysis was performed to better understand the experimental data, with significant differences being observed between treated and control samples (Fig. 2). Results showed significant differences between conditions applied, namely the heating mode $(\mathrm{OH}$ or conventional) or the intensity of the electric field during $\mathrm{OH}$.

According to the obtained results, no significant differences $(p>0.05)$ were found between control samples with different conductivities, suggesting that salt addition has no impact on extracted antioxidant activity (results not shown).

Concerning polyphenolic content, the method of extraction is more important on the recovery of these compounds, with a more significant effect than with electric field effect (Fig. 2). The complexity and diversity of polyphenols (molecular size and structure) makes it difficult to anticipate the effect of electric field (Elez-Martínez et al., 2017). Therefore, the following results consider the extraction of individual polyphenols, mainly three relevant polyphenolic compounds 

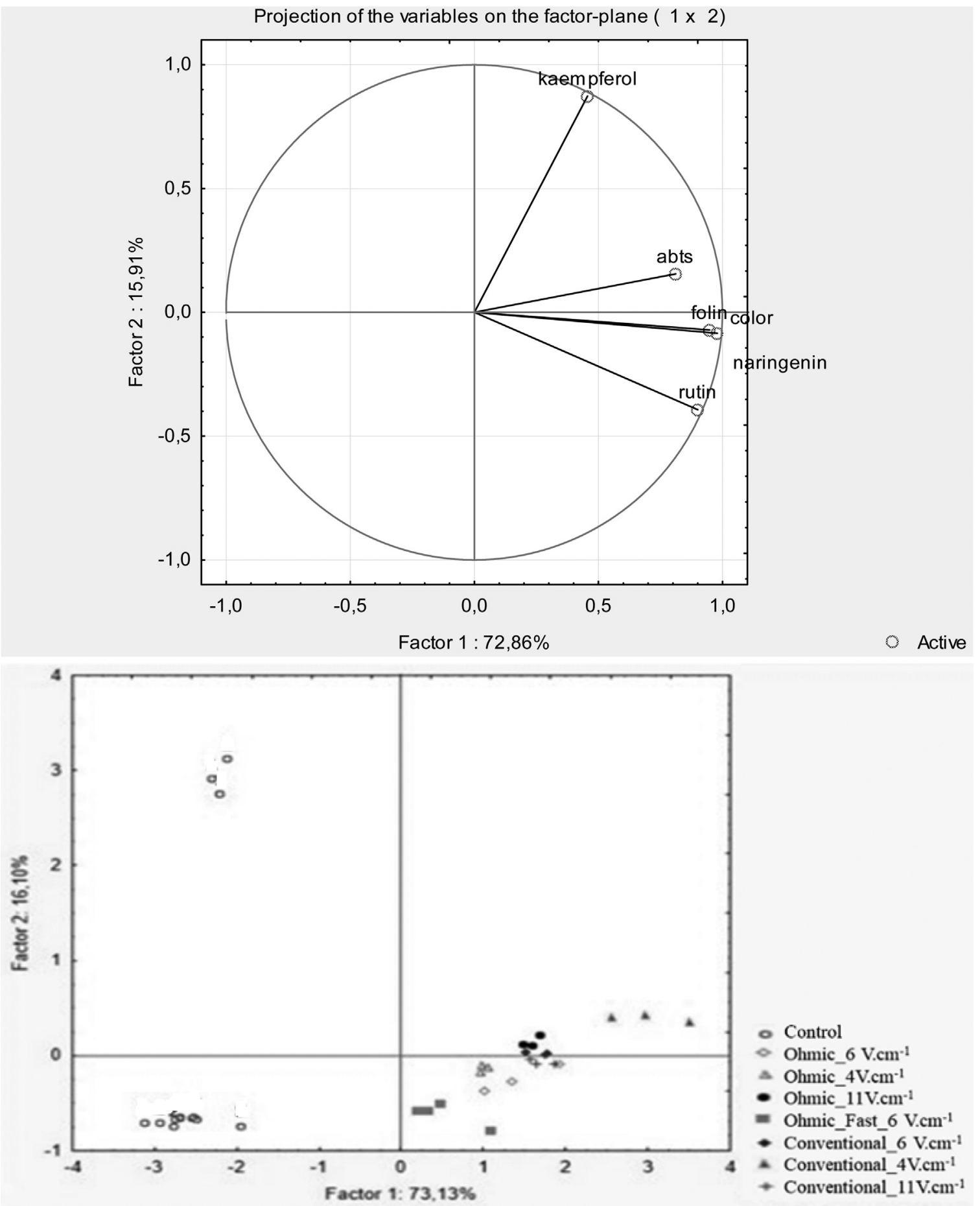

Fig. 2 - PCA analysis to variables studied.

that were found to be present: naringenin, rutin and kaempferol.

Electric fields have different effects on the recovery of each individual polyphenol compound (Fig. 2); moreover significant differences were observed between conventional and $\mathrm{OH}$ extractions $(p<0.05)$. According PCA analysis a correlation between antioxidant activity and kaempferol extraction were observed. $\mathrm{OH}$ at $11 \mathrm{~V} \mathrm{~cm}^{-1}$ influence both antioxidant activity and kaempferol extraction, while $\mathrm{OH}$ at moderate $\left(6 \mathrm{~V} \mathrm{~cm}^{-1}\right)$ and low $\left(4 \mathrm{~V} \mathrm{~cm}^{-1}\right)$ electric fields influences color, naringenin and rutin extraction. Results suggests that at higher electric fields application, there are glycosides break bonds, in chemical structural of rutin with kaempferol formation, as Khan et al. (2018), refers the electromagnetic fields could have the capacity to break down, both -ester and glycoside-bound phenolic compounds.

$\mathrm{OH}$ and conventional extractions at $6 \mathrm{~V} \mathrm{~cm}^{-1}$ gave rise to an increase in rutin concentration of 82 and $79 \%$, respectively, when compared to control sample. At this frequency pores can be formed across cell wall altering the membrane permeability and consequently to accelerating the diffusion kinetics (Kaur et al., 2016b; Maroun et al., 2017). In addition, the OH extraction used to achieve a high temperature in few seconds, allowed an increase of 77 and $61 \%$ in rutin and naringenin extraction, respectively, compared to the control sample. No significant differences were obtained between conventional and fast $\mathrm{OH}$ extraction $(p>0.05)$. However, it is important to highlight that it was possible to reduce total extraction treatment time for 

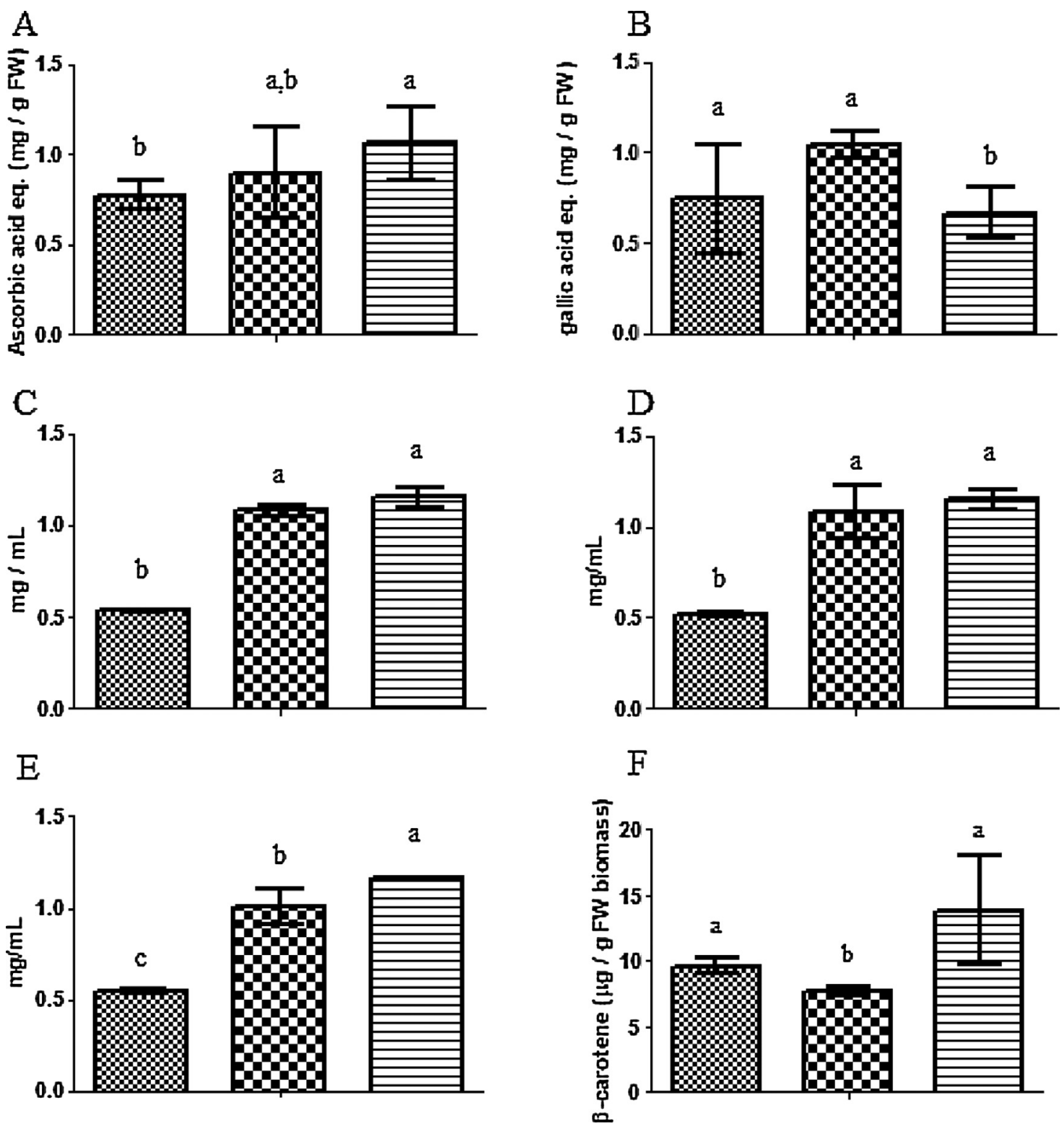

Fig. 3 - Electric fields effects on A) antioxidant activity, B) total polyphenolic content, C) rutin, D) kaempferol, E) naringenin and F) total carotenoids content; $4 \mathrm{~V} \mathrm{~cm}^{-1}, \mathbf{W \mathrm { V } \mathrm { cm }}{ }^{-1}, \square 11 \mathrm{~V} \mathrm{~cm}^{-1}$. a Different letters represent significant differences $(p<0.05)$ in comparison to the original content.

approximately $16 \%$ through $\mathrm{OH}$, as less time was required to reach the target temperature, reducing the overall processing time.

Both electric field effects and methods of extraction have significant effects on kaempferol and rutin recovery. OH application allows the temperature of extraction to be reached faster than the conventional method, reducing the overall processing time. The application of a fast heating process may be important on the preservation of heat sensitive phenolic compounds. At the same time, the fast heating and electroporation effects can cause cellular heat stress and consequently structural damages, enhancing the release of certain phenolic compounds (Khajehei et al., 2017; Sakr and Liu, 2014; Sastry, 2008).

Therefore, for a better understanding of the electric field influence, the results were normalized according to Eq. (2), as shown in Fig. 3.

Electric field effect $=\frac{(\text { Ohmic } A-\text { ControlA })}{(\text { ConventionalA }- \text { ControlA })}$
Normalization of the experimental data revealed that significant differences were found between 4 and $11 \mathrm{~V} \mathrm{~cm}^{-1}$ and 6 and $4 \mathrm{~V} \mathrm{~cm}^{-1}$ for all individual compounds detected. The application of 6 and $11 \mathrm{~V} \mathrm{~cm}^{-1}$ electric fields showed higher individual compounds recoveries from tomato extracts when compared with $4 \mathrm{~V} \mathrm{~cm}^{-1}$ (see Fig. 3), being this difference significant $(p<0.05)$. Relatively to rutin and kaempferol extraction, no significant difference was detected between 6 and $11 \mathrm{~V} \mathrm{~cm}^{-1}$, while to naringenin there was significant differences between the electric fields applied. Joule effect can induce an electro and thermal-permeabilization of cell membranes, causing disturbances on their permeability, structural alterations, contributing in release of higher amounts of polyphenol compounds (Khajehei et al., 2017). In addition, it was detected two groups of polyphenols (rutin and kaempferol are flavonols and naringenin is a flavanone) with different structural comportments. It means, the increased of naringenin with the electric field application could be attributed to the induction of flavanone synthase when $\mathrm{OH}$ treatments were applied (Vallverdú-Queralt et al., 2012). 
Regarding carotenoids, see Fig. 3, significant differences were found at different levels of MEF applied $(p>0.05)$. The effect of electrical fields on bioactive compounds such as carotenoid needs to be better understood through systematic and fundamental studies. Notwithstanding the low quantities of carotenoids recovered (5-10 $\mu \mathrm{g})$, OH may be a useful source to extract these compounds without their degradation.

In addition, a selective extract can be obtained depending on the treatment applied, as $\mathrm{OH}$ can be used to selectively extract some compounds without reducing the efficiency of the extraction process. This is the case for rutin extraction when a fast $\mathrm{OH}$ is applied. For kaempferol extraction, both $\mathrm{OH}$ with high electric field and conventional treatments with moderate conductivity may be applied. Nevertheless, if the objective is to obtain extracts rich in polyphenolic content, or high in rutin and naringenin, an ohmic heating with 6 and $11 \mathrm{~V} . \mathrm{cm}^{-1}$ may have shown to be promising approaches. These results may suggest a selective extraction of certain compounds depending on the electric field applied. Thus, $\mathrm{OH}$ seems to be an interesting processing tool to improve the extraction of valuable components from vegetable tissues (Medina-Meza and Barbosa-Cánovas, 2015; Xue and Farid, 2015).

\section{Conclusion}

Results suggest that $\mathrm{OH}$ is an efficient extraction process for polyphenols from tomato by-products with a $58 \%$ higher recovery rate than control samples. Relatively to the lycopene and $\beta$-carotene compounds the optimization process allows their extraction from tomato by-products without addition of organic solvents (usually useful to obtain these lipophilic compounds). Nevertheless, their extraction yields were lesser when compared with conventional method and new approaches were needed. The Joule effect and fast heating in association with high electric field intensities allowed a significant recovery of polyphenols and carotenoids compounds. In addition, there are a resourceful polyphenols and carotenoids recovery when 6 and $11 \mathrm{~V} \mathrm{~cm}^{-1}$ electric fields were applied.

In conclusion, $\mathrm{OH}$ may be an efficient - as well as selective - technique for the extraction of compounds from tomato by-products that allows same yields to be achieved as in conventional processes but at a higher extraction rate (less time). Furthermore, this technique can be used as an alternative to conventional organic solvents methods to extract both polyphenols and carotenoids compounds.

\section{Conflicts of interest}

The authors declare no conflict of interests.

\section{Acknowledgements}

The authors would like to thank to the project Co-promoção n 016403, "MULTIBIOREFINERY", supported by Programa Operacional Competitividade e Internacionalização, and by Programa Operacional Regional de Lisboa, on its component FEDER, and by Portuguese Foundation for Science and Technology (FCT) and project UID/Multi/50016/2019, administrated by FCT. Furthermore, his study was supported by the FCT under the scope of the strategic funding of UID/BIO/04469/2019 unit and BioTecNorte operation (NORTE01-0145-FEDER-000004) funded by the European Regional
Development Fund under the scope of Norte2020 - Programa Operacional Regional do Norte. The author Marta Coelho would like to acknowledge FCT for your $\mathrm{PhD}$ grant with the reference [grant number SFRH/BD/111884/2015].

\section{References}

Aguilar-Machado, D., Morales-Oyervides, L., Contreras-Esquivel, J.C., Aguilar, C., Méndez-Zavala, A., Raso, J., Montañez, J., 2017. Effect of ohmic heating processing conditions on color stability of fungal pigments. Food Sci. Technol. Int. 23, 338-348, http://dx.doi.org/10.1177/1082013216689514.

Ameer, K., Shahbaz, H.M., Kwon, J.H., 2017. Green extraction methods for polyphenols from plant matrices and their byproducts: a review. Compr. Rev. Food Sci. Food Saf. 16, 295-315, http://dx.doi.org/10.1111/1541-4337.12253.

Anderson, A.K., Finkelstein, R., 1919. A study of the electro-pure process of treating milk. J. Dairy Sci. 2, 374-406, http://dx.doi.org/10.3168/jds.s0022-0302(19)94338-4.

Brochier, B., Mercali, G.D., Marczak, L.D.F., 2018. Effect of ohmic heating parameters on peroxidase inactivation, phenolic compounds degradation and color changes of sugarcane juice. Food Bioprod. Process. 111, 62-71, http://dx.doi.org/10.1016/j.fbp.2018.07.003.

Caldas, T.W., Mazza, K.E.L., Teles, A.S.C., Mattos, G.N., Brígida, A.I.S., Conte-Junior, C.A., Borguini, R.G., Godoy, R.L.O., Cabral, L.M.C., Tonon, R.V., 2018. Phenolic compounds recovery from grape skin using conventional and non-conventional extraction methods. Ind. Crops Prod. 111, 86-91, http://dx.doi.org/10.1016/j.indcrop.2017.10.012.

Coelho, M., Pereira, R.N., Teixeira, J.A., Pintado, M., 2017. Valorization of tomato wastes: influence of ohmic heating process on polyphenols extraction time. In: Extended Abstract of Vienna Polyphenols 2017. Archives of International Society of Antioxidants in Nutrition, Vienna, pp. 37-40, http://dx.doi.org/10.18143/AISANH_v5i2_11.

Dewanto, V., Xianzhong, W., Adom, K.K., Liu, R.H., 2002. Thermal processing enhances the nutritional value of tomatoes by increasing total antioxidant activity. J. Agric. Food Chem. 50, 3010-3014, http://dx.doi.org/10.1021/jf0115589.

Do, Q.D., Angkawijaya, A.E., Tran-Nguyen, P.L., Huynh, L.H., Soetaredjo, F.E., Ismadji, S., Ju, Y.-H., 2014. Effect of extraction solvent on total phenol content, total flavonoid content, and antioxidant activity of Limnophila aromatica. J. Food Drug Anal. 22, 296-302, http://dx.doi.org/10.1016/J.JFDA.2013.11.001.

El Darra, N., Grimi, N., Vorobiev, E., Louka, N., Maroun, R., 2013. Extraction of polyphenols from red grape pomace assisted by pulsed ohmic heating. Food Bioproc. Technol. 6, 1281-1289, http://dx.doi.org/10.1007/s11947-012-0869-7.

Elez-Martínez, P., Odriozola-Serrano, I., Oms-Oliu, G., Soliva-Fortuny, R., Martín-Belloso, O., 2017. Effects of pulsed electric fields processing strategies on health-related compounds of plant-based foods. Food Eng. Rev. 9, 213-225, http://dx.doi.org/10.1007/s12393-017-9162-x.

FAO, 2017. FAOSTAT [WWW document]. In: Food and Agriculture Organization of the United Nations. http://www.fao.org/faostat/en/\#home.

Figueiredo-González, M., Valentão, P., Andrade, P.B., 2016. Tomato plant leaves: from by-products to the management of enzymes in chronic diseases. Ind. Crops Prod. 94, 621-629, http://dx.doi.org/10.1016/j.indcrop.2016.09.036.

Galanakis, C.M., 2017. Nutraceutical and Functional Food Components: Effects of Innovative Processing Techniques. Academic Press.

Gavahian, M., Farahnaky, A., Sastry, S., 2016. Ohmic-assisted hydrodistillation: a novel method for ethanol distillation. Food Bioprod. Process. 98, 44-49, http://dx.doi.org/10.1016/j.fbp.2015.11.003.

Gião, M.S., González-Sanjosé, M.L., Rivero-Pérez, M.D., Pereira, C.I., Pintado, M.E., Malcata, F.X., 2007. Infusions of Portuguese medicinal plants: dependence of final antioxidant capacity 
and phenol content on extraction features. J. Sci. Food Agric. 87, 2638-2647, http://dx.doi.org/10.1002/jsfa.3023.

Hackett, M.M., Lee, J.H., Francis, D., Schwartz, S.J., 2006. Thermal stability and isomerization of lycopene in tomato oleoresins from different varieties. J. Food Sci. 69, 536-541, http://dx.doi.org/10.1111/j.1365-2621.2004.tb13647.x.

Heuvelink, E., 2018. Tomatoes. In: Heuvelink, E. (Ed.), Crop Production Science in Horticulture. CABI Publishing, Boston, MA, p. 378.

Hodges, D.M., DeLong, J.M., Forney, C.F., Prange, R.K., 1999. Improving the thiobarbituric acid-reactive-substances assay for estimating lipid peroxidation in plant tissues containing anthocyanin and other interfering compounds. Planta 207, 604-611, http://dx.doi.org/10.1007/s004250050524.

Hogervorst Cvejić, J., Atanacković Krstonošić, M., Bursać, M., Miljić, U., 2017a. Chapter 7-polyphenols. In: Nutraceutical and Functional Food Components., pp. 203-258, http://dx.doi.org/10.1016/B978-0-12-805257-0.00007-7.

Hogervorst Cvejić, J., Atanacković Krstonošić, M., Bursać, M., Miljić, U., 2017b. Polyphenols. In: Nutraceutical and Functional Food Components. Elsevier, pp. 203-258, http://dx.doi.org/10.1016/B978-0-12-805257-0.00007-7.

Kaur, N., Singh, A.K., 2016. Ohmic heating: concept and applications-a review. Crit. Rev. Food Sci. Nutr. 56, 2338-2351, http://dx.doi.org/10.1080/10408398.2013.835303.

Kaur, R., Gul, K., Singh, A.K., 2016a. Nutritional impact of ohmic heating on fruits and vegetables-a review. Cogent Food Agric., http://dx.doi.org/10.1080/23311932.2016.1159000.

Kaur, R., Gul, K., Singh, A.K., 2016b. Nutritional impact of ohmic heating on fruits and vegetables-a review. Cogent Food Agric. 2, 1159000, http://dx.doi.org/10.1080/23311932.2016.1159000.

Khajehei, F., Niakousari, M., Damyeh, M.S., Merkt, N., Claupein, W., Graeff-Hoenninger, S., 2017. Impact of ohmic-assisted decoction on bioactive components extracted from yacon (Smallanthus sonchifolius Poepp.) leaves: comparison with conventional decoction. Molecules 22, http://dx.doi.org/10.3390/molecules22122043.

Khan, M.K., Ahmad, K., Hassan, S., Imran, M., Ahmad, N., Xu, C., 2018. Effect of novel technologies on polyphenols during food processing. Innov. Food Sci. Emerg. Technol. 45, 361-381, http://dx.doi.org/10.1016/j.ifset.2017.12.006.

Kim, H.S., Chin, K.B., 2016. Evaluation of different drying temperatures on physico-chemical and antioxidant properties of water-soluble tomato powders and on their use in pork patties. J. Sci. Food Agric. 96, 742-750, http://dx.doi.org/10.1002/jsfa.7141.

Kimura, M., Rodriguez-Amaya, D.B., Godoy, H.T., 1990. Assessment of the saponification step in the quantitative determination of carotenoids and provitamins A. Food Chem. 35, 187-195, http://dx.doi.org/10.1016/0308-8146(90)90032-Y.

Kumar, T., 2018. A review on ohmic heating technology: principle, applications and scope. Int. J. Agric. Environ. Biotechnol. 11, http://dx.doi.org/10.30954/0974-1712.08.2018.10.

Lapornik, B., Prošek, M., Golc Wondra, A., 2005. Comparison of extracts prepared from plant by-products using different solvents and extraction time. J. Food Eng. 71, 214-222, http://dx.doi.org/10.1016/j.jfoodeng.2004.10.036.

Loypimai, P., Moongngarm, A., Chottanom, P., Moontree, T., 2015. Ohmic heating-assisted extraction of anthocyanins from black rice bran to prepare a natural food colourant. Innov. Food Sci. Emerg. Technol. 27, 102-110, http://dx.doi.org/10.1016/j.ifset.2014.12.009.

Maroun, R.G., Rajha, H.N., Vorobiev, E., Louka, N., 2017. Emerging technologies for the recovery of valuable compounds from grape processing by-products. In: Handbook of Grape Processing By-Products: Sustainable Solutions., pp. 155-181, http://dx.doi.org/10.1016/B978-0-12-809870-7.00007-7.

Medina-Meza, I.G., Barbosa-Cánovas, G.V., 2015. Assisted extraction of bioactive compounds from plum and grape peels by ultrasonics and pulsed electric fields. J. Food Eng. 166, 268-275, http://dx.doi.org/10.1016/j.jfoodeng. 2015.06.012.
Nunes, I.L., Mercadante, A.Z., 2004. Obtenção de cristais de licopeno a partir de descarte de tomate. Food Sci. Technol. (Campinas) 24, 440-447.

Oliveira, A., Coelho, M., Alexandre, E.M.C., Gomes, M.H., Almeida, D.P.F., Pintado, M., 2015a. Effect of modified atmosphere on phytochemical profile of pasteurized peach pures. Lwt: Food Sci. Technol. 64, 520-527, http://dx.doi.org/10.1016/j.lwt.2015.06.023.

Oliveira, C., Ferreira, A.C., Costa, P., Guerra, J., De Pinho, P.G., 2004. Effect of some viticultural parameters on the grape carotenoid profile. J. Agric. Food Chem. 52, 4178-4184, http://dx.doi.org/10.1021/jf0498766.

Oliveira, C.M., Barros, A.S., Silva Ferreira, A.C., Silva, A.M.S., 2015b. Influence of the temperature and oxygen exposure in red Port wine: a kinetic approach. Food Res. Int. 75, 337-347, http://dx.doi.org/10.1016/j.foodres.2015.06.024.

Pataro, G., Barca, G.M.J., Pereira, R.N., Vicente, A.A., Teixeira, J.A., Ferrari, G., 2014. Quantification of metal release from stainless steel electrodes during conventional and pulsed ohmic heating. Innov. Food Sci. Emerg. Technol. 21, 66-73, http://dx.doi.org/10.1016/j.ifset.2013.11.009.

Pereira, R.N., Rodrigues, R.M., Genisheva, Z., Oliveira, H., de Freitas, V., Teixeira, J.a., Vicente, A.a., 2016. Effects of ohmic heating on extraction of food-grade phytochemicals from colored potato. LWT: Food Sci. Technol. 74, 493-503, http://dx.doi.org/10.1016/j.lwt.2016.07.074.

Pereira, R.N., Souza, B.W.S., Cerqueira, M.A., Teixeira, J.A., Vicente, A.A., 2010. Effects of electric fields on protein unfolding and aggregation: influence on edible films formation. Biomacromolecules 11, 2912-2918, http://dx.doi.org/10.1021/bm100681a.

Pereira, R.N., Teixeira, J.A., Vicente, A.A., Cappato, L.P., da Silva Ferreira, M.V., da Silva Rocha, R., da Cruz, A.G., 2018. Ohmic heating for the dairy industry: a potential technology to develop probiotic dairy foods in association with modifications of whey protein structure. Curr. Opin. Food Sci. 22, 95-101, http://dx.doi.org/10.1016/j.cofs.2018.01.014.

Rajha, H.N., Boussetta, N., Louka, N., Maroun, R.G., Vorobiev, E., 2014. A comparative study of physical pretreatments for the extraction of polyphenols and proteins from vine shoots. Food Res. Int. 65, 462-468, http://dx.doi.org/10.1016/j.foodres.2014.04.024.

Ramaswamy, H.S., Marcotte, M., Sastry, S., Abdelrahim, K., 2014. Ohmic heating in food processing. Ohmic Heat. Food Process., http://dx.doi.org/10.1201/b16605.

Ribeiro, J., Boussetta, N., Blouet, C., Cristina, I., Damasceno, L., Marczak, F., Vorobiev, E., 2015. Effect of pulsed electric fields and high voltage electrical discharges on polyphenol and protein extraction from sesame cake. Innov. Food Sci. Emerg. Technol. 29, 170-177, http://dx.doi.org/10.1016/j.ifset.2015.02.011.

Sakr, M., Liu, S., 2014. A comprehensive review on applications of ohmic heating (OH). Renew. Sustain. Energy Rev. 39, 262-269, http://dx.doi.org/10.1016/j.rser.2014.07.061.

Sastry, S.K., 2008. Ohmic heating and moderate electric field (MEF) processing. Food Sci. Technol. Int. 14, 419-422, http://dx.doi.org/10.1177/1082013208098813.

Seidi Damyeh, M., Niakousari, M., 2017. Ohmic hydrodistillation, an accelerated energy-saver green process in the extraction of Pulicaria undulata essential oil. Ind. Crops Prod. 98, 100-107, http://dx.doi.org/10.1016/j.indcrop.2017.01.029.

Seybold, C., Fröhlich, K., Bitsch, R., Otto, K., Böhm, V., 2004. Changes in contents of carotenoids and vitamin e during tomato processing. J. Agric. Food Chem. 52, 7005-7010, http://dx.doi.org/10.1021/jf049169c.

Singleton, V.L., Rossi Jr, J.A., 1965. Colorometry of total phenolics with phosphomolybdic-phosphotungstic acid reagents. Am. J. Enol. Vitic. 16, 144-158, http://dx.doi.org/10.12691/ijebb-2-1-5.

Tommonaro, G., Poli, A., De Rosa, S., Nicolaus, B., 2008. Tomato derived polysaccharides for biotechnological applications: chemical and biological approaches. Molecules 13, 1384-1398, http://dx.doi.org/10.3390/molecules13061384. 
Toor, R.K., Savage, G.P., 2005. Antioxidant activity in different fractions of tomatoes. Food Res. Int. 38, 487-494,

http://dx.doi.org/10.1016/j.foodres.2004.10.016.

Vallverdú-Queralt, A., Odriozola-Serrano, I., Oms-Oliu, G.,

Lamuela-Raventós, R.M., Elez-Martínez, P., Martín-Belloso, O., 2012. Changes in the polyphenol profile of tomato juices processed by pulsed electric fields. J. Agric. Food Chem. 60, 9667-9672, http://dx.doi.org/10.1021/jf302791k.

Xue, D., Farid, M.M., 2015. Pulsed electric field extraction of valuable compounds from white button mushroom (Agaricus bisporus). Innov. Food Sci. Emerg. Technol. 29, 178-186, http://dx.doi.org/10.1016/j.ifset.2015.03.012. 